\title{
"History of the Establishment of Overseas Bureau and of the Government-Fund Students" and the Development Law of Overseas Education
}

\author{
Qingbo Jiang \\ School of Humanities \\ Jinan University \\ Zhuhai, China
}

\begin{abstract}
More than a century ago, the Qing government sent four batches of government-fund students to the United States as an attempt to strengthen the country, but the movement ended up hastily. Today, China's reform and opening up is taking place, and the wave of studying abroad is on the rise. Looking back on the study abroad movement a hundred years ago, there can be many enlightenment: advanced education modes will eventually spread through cultural exchanges; overseas education needs continuous policy support to achieve the effect; overseas education developed in necessity and accident, and it has to give full play to the role of "people". How to further introspect and improve the thinking and working methods of overseas education is a problem directly faced by the current operating system of overseas education.
\end{abstract}

Keywords-Overseas Bureau; study in foreign countries; education; law

\section{INTRODUCTION}

In 1939, Mr. Rong Shangqian wrote "History of the Establishment of Overseas Bureau and of the Governmentfund Students" in English, which recorded the experiences and twists and turns of the first batch of government-fund students in modern China. Later, Mr. Wang Minruo translated it into Chinese and then it was published by Zhuhai Publishing Company, [1] and became a part of series books about Zhuhai History and Culture. Although the social environment a century ago is very different from today, the situation of overseas education in the book reflects the problems in the current stage of overseas education, which is still enough to cause us some regular thinking about overseas education. Based on the research on Chinese overseas students, the author talks about the enlightenments he felt in the course of reading "History of the Establishment of Overseas Bureau and of the Government-fund Students", and hopes to set the ball rolling and make overseas education plays a greater role in social development during a multiaspect discussion.

\section{ENLIGHTENMENT ONE: SPREADING LAW OF STUDYING ABROAD EDUCATION IN INTERNATIONAL CULTURAL EXCHANGE}

Since the Qing government sent young children to the United States in 1872, until the reform and opening up, China had four waves of studying abroad include: Japan wave in the late Qing Dynasty and the early Republic of China, France wave during the May Fourth Movement, Soviet Union wave in the 1920s, and The United Sates wave in 1940s. The motivation of the people to study abroad is always closely related to the international environment (politics, economy, international situation, study abroad policy, etc.)

After the Opium War, national crisis is imminent, and what China lacked was the civilization that would make the country rich and strong and the education that conveyed Western civilization. The Qing government sent the first batch of young children to study in the United States in 1872 , which was based on the consideration of fostering the Qing government's future pillars after they finally accepted Rong Hong's suggestions. [2] Therefore, when young children went to the United States, the general direction was to "know learn knowledge and techniques, and then transferred them to military administration and shipping administration schools." The intention of focusing on military affairs was very obvious. [3]

Judging from the situation in the United States, in the 1870s, pragmatism emerged as a philosophical idea Pragmatism system includes pioneering spirit, innovative ideas, pragmatic ideas, benefits, quality, risks, competition, equality and other concepts, as well as the abandonment of traditional habits, inability to make progress, find contentment in poverty, and other habits. It also includes the bold pursuit of new trends such like dare to break the rules, aggressive and creative. ${ }^{1}$

Pragmatism originally originated as a philosophical idea in the 1870 s and became popular in the 1930s. American physics, mathematics, and logician Pierce first applied the principle of "Pragmatism" to philosophy, and proposed the concept of "Pragmatism." After 1898 American psychologist and philosopher James applied the principle of 
abroad. It took decades of studying abroad in the ancient times, for example, the study period of students from Xinluo and other countries in the Tang Dynasty is "normally ten years", [5] some international students have even studied in China for decades. [6] Such as the Prince Xinluo Jin Renwen, he lived in Tang Dynasty for 23 years; [7] another Xinluo people Jin Yunfu lived for 26 years. [8] A longer study period ensures that international students have a more comprehensive understanding and grasp the cultural essence of developed countries. After returning to their countries, most of them were reused by their rulers and played a huge role in many fields.

It was pointed out that during the Westernization Movement, few of the overseas students who returned China entered academic ideological circle. [9] Some scholars believe that during the Westernization Movement period, the purpose of running the school was to serve the feudal ruling class. The imperial examination system was not completely negated, and the study of the West was only limited to science and technology, "this objectively created the conditions for the imperialists to carry out cultural aggression and spiritual plunder in China, and deepened the semi-colonial and semi-feudalization of Chinese education." [10] What are the limitations of school running of Westernization Movement? We should naturally look at the specific historical conditions, and let us put it aside first. From the perspective of studying Western science and technology, we have to admit that this is because we have a quite distance with West World during the process of our cultural development. The purpose of studying the West is to shorten this distance, to strengthen ourselves in national strength, and actually to supplement ourselves culturally.

In short, advanced education models will eventually spread through cultural exchanges. The questions, such as where to study abroad and how long to stay abroad, have a lot to do with the domestic comprehensive environment of the sending and receiving countries of the international students and the trend of civilization development in the international environment. This is the case in ancient and modern times, and also the same as we learn the advanced education model in the West. We must be clear about our own shortcomings, learn from the strengths of other countries' education systems, and must combine existing educational practices and educational foundations, as $\mathrm{Mr}$. Zhu Gaozheng advocates, "the pursuit of modernization cannot be separated from tradition; no country in the world can completely deny its own cultural tradition and complete modernization". In this regard, the education in Germany and Japan provides us with a reference. "The success of modernization in Germany and Japan lies in their ability to directly grasp the direction of the development of the entire nation based on their own traditions, thus confirming the subjectivity of culture." [11] In a word, we must treat our educational reality with a pragmatic attitude.

\section{ENLIGHTENMENT TwO: OVERSEAS EDUCATION NEEDS CONTINUOUS POLICY SUPPORT}

Overseas education can be actively promoted on the basis of national conditions, and it needs specific planning or 
policies to guide it. In this issue, the role of "people", or the overall quality of the planner, is of great importance. Looking at the history of China, there are a lot of examples of policies that twist developed because they were designed by different people. History has always meandered in such bumps. To this day, this phenomenon still deserves our serious review and reflection.

The establishment and operation of the Overseas Bureau embodies the efforts of Rong Hong since he graduated from Yale University, and also embodies the ideals of court officials such as Zeng Guofan, Li Hongzhang, and Ding Richang. They hope that the country send students to study abroad and serve for China after graduation in order to deal with the ever-changing world situation. [12] It can be said that these people's visions exceeded the ordinary people of the same era.

During the Westernization Movement, Zhang Zhidong proposed that students should be sent to study in Japan; during the Reform Movement of 1898, reformers tried hard to promote people learn from Japan. ${ }^{3}$ So there are scholars believed that the Qing government's policy of encouraging students to study in Japan has accumulated talents in both ideology and organizational strength, although objectively "unconsciously constructed the foundation of the 1911 Revolution and its own graveyard." [13]

After returning to China, most of the returned students were arranged in various departments related to foreign affairs, and they were rewarded with the official rank. This approach has played a role in stimulating students to study abroad, and it has also had a huge impact on the overall policy of overseas students in the late Qing Dynasty. [14] Returned students have made great achievements in many fields. As far as the original intention of sending students to study abroad is concerned, the Qing government achieved the expected purpose to a certain extent.

However, the reason for the end of the Overseas Bureau is precisely in the eyes of the competent officials, "He claimed that these children have all been Americanized and stateless, if they continue to complete their studies in the United States, there will be no benefit to China, only harm." [15] As a result, the Overseas Bureau was ordered to suspend. Fifteen years later, in the case of a shortage of talents, $\mathrm{Li}$ Hongzhang asked strangely why Rong Hong had dissolved the Overseas Bureau. [16] Overseas Affairs was born because of people and suspend because of people, how many regrets did the development of Chinese society leave behind

Kang Youwei proposed in the "The presentation of Meiji Political Reform of Japan" that learn from Japan is not only a shortcut, but also does not violate the ancestral law: "The new law in Europe and America and the good rules of Japan are found in our mainland China. It 's almost 300 years since Europe and the United States have created a governance system, Japan learned from them and established a governance system with 30 years, if we greatly learn from Japan, then it will only took three years to created the structure, five years to prepare the provision, eight years to see the result and ten years will be enough to finish the whole system." It was under the strong encouragement of the Reformers that Emperor Guangxu resolutely issued an imperial edict:" Order the provincial governors select local bright students to go to Japan for overseas study." for this? History cannot assume. Although the establishment, operation, and suspension of the Overseas Bureau were just a drop of water in history, it reflected that: in a society without a sound system and guarantee, any measure may be disturbed by humans and fall off toward the close. Therefore, with regard to the current operating system for overseas education, how we can further reflect and improve our thinking and working methods should be given full attention.

It is worth mentioning that all education expenses of overseas students are paid by the government, and the costs of post-graduate studies and study tours to some European countries are also included. [17] This greatly reduces the burden on students. Historically, this measure of studying abroad was not the first. The Silla and the Japanese government, which sent a large number of students to the Sui and Tang dynasties, all provide certain amount of money for the students. In addition, the Tang government also ordered Honglusi or Jingzhaofu to provide "monthly grain for foreign students" and "seasonal clothing" to the foreign students who studied in Guozijian. ${ }^{4}$ These measures have enabled students from less wealthy families to focus on their studies and try to minimize unnecessary interference, thereby creating conditions for the country's future talent reserves.

At the same time, we have also seen that in China, the "Hope Project to Realize Dream" carried out by the China Youth Development Foundation is also solving the problems of studying for more college and high school students and creating conditions for schooling., which are very forwardlooking measures in terms of the development of our country and our nation.

For non-Chinese citizens studying at Chinese institutions of higher learning or conducting scientific research, including undergraduates, postgraduates, doctoral students, ordinary advanced students and senior advanced students, the Chinese government has also formulated and is continuously improving the Chinese government scholarship funding system and increasing funding standard. For example, in 2008, the Ministry of Education and Ministry of Finance issued a "Notice on adjusting the standard of living expenses for foreign students' scholarships", and in 2015 the government issued "Notice on Improving the Chinese Government's Scholarship Funding System and Raising the Funding Standards". The awards introduced in 2015 for students studying in China have a wider range of funding and greater funding strength. The subsidy covers tuition exemption, accommodation fee exemption, subsidized living expenses, and comprehensive medical insurance. In addition,

\footnotetext{
4 According to Cui Zhiyuan's "Collected Works of Guyun" Volume 1 "Sent Suwei Student Leaders to the Tang Dynasty" described in the second year of Guangqi (886), Xinluo sent Cui Shenzhi and other eight students to Tang, the Emperor of Xinluo pleaded: "We want to send overseas students to Tang Dynasty to learn the advanced technologies and knowledge, the book expenses has already been provided, but for the other fees and clothing, please be kind and provide for them, since the distance between us and Tang is too far, it took them 3 months to arrive there, so please let them study for ten years. " $\mathrm{H}$ hoped the Tang government "specially declared Hongluo Temple provide monthly fees for their overseas students and the seasonal clothing."
} 
scholarship students with outstanding academic performance can also enjoy outstanding international student awards. [18]

It is not enough to be able to find out and solve problems in overseas education, but also to cultivate a solid and persistent habit when young people receive domestic education. According to the "Southern Metropolis Daily" reported on November 5, 2006: a school in Shenzhen organized students to carry out social practice, 380 junior middle school students traveled to Guizhou to carry out the "Hand in Hand West Trip" poverty-stricken students alleviation activities by plane, the cost per student was up to 2000 Yuan. This activity has aroused people's heated discussion in society. From the perspective of student aid and poverty alleviation, one cannot but ask people such questions: How long can such poverty alleviation actions persist? It is not uncommon for us to see this kind of poverty alleviation activity. In 2018, the media also disclosed an incident of poverty alleviation fraud. A principal in Xinfeng County, Jiangxi Province, was punished for the fake students aid. [19] If we cultivate students in this fake and fraud way, then our education quality is worth serious consideration.

How to make more people better educated is a serious problem the Chinese people facing now, and it is also an issue that cannot be avoided in building a harmonious society. Overseas education should be and must be supported by continuous policies. Considering our country's long history and social tradition, this problem requires us to concentrate more energy to face and resolve, and find a suitable connection between tradition and the future.

\section{ENLIGHTENMENT THREE: THE LAW OF PROGRESS OF OVERSEAS EDUCATION IN THE NECESSITY AND OCCASIONALITY}

As mentioned above, the establishment and shut down of the Overseas Bureau has shown that the overseas education should have continuous policy support from both sides, and there should be a group of advocates or organizers with longterm view. But it is undeniable that the success of overseas education has certain occasionality. The person who asked the Qing government to send overseas students to Western countries was not Rong Rong, but he made specific suggestions and contributed to this matter. ${ }^{5}$ In 1927 , Mr.

According to the photocopy of "The administration of ethnic affairs (Tongzhi Dynasty)", Volume 15 of the Beijing Palace Museum and the 1957 edition of "A Letter from Li Hongzhang to the General Administration · Haiphong Archives · Machine Bureau (1)" , in 1863 (second year of Tongzhi), the selected county magistrate Gui Wencan reported to the Qing court: "I heard that Japan sent young children to Russia and the United States to learn how to make guns, ships,lead medicine and all weapons. The study period is about ten years. If this matter is true, Japan will be strong and we must worry about this in advance. Our country should also learn the method of making ship and artillery in other countries. "In this regard, Prime Minister of the Ministry of foreign Affairs Yi Xin approved this. In March 1865, Yi Xin sent the banner soldiers to study weapons manufacturing in foreign countries, and he discussed it with Li Hongzhang in secret. In May, Li wrote back and said that he sent people to study abroad, "From the reasoning and the situation perspective, it is a necessity for the future. I just did not mention it to anyone." It can be seen that the important officials such like Yi Xin and Li Hongzhang, also realized that sending people to study abroad is a necessary move in the future. It is this background and the factor that
Shu Xincheng said in the "History of Studying abroad in Modern China": I can't say that without Rong Hong, China will not have overseas students, but it will not happen so early and maybe they will be sent to study abroad in another way." [20]

The Qing government sent young children aged 12 to 16 to study abroad. The reason is that the younger they are, the easier it is to learn foreign languages and scientific and technological knowledge, and they are free from the stress of their families. At that time, most people in China did not realize the value of Western knowledge; and for the nobles who despised Western knowledge and has a clear official path, study abroad has no attraction to them. Therefore, most of the families who sent their children abroad were well-off family with enlightened parents. [21] This was a normal phenomenon in the social environment at the time, but to a certain extent, it also showed that the establishment of the Overseas Bureau and overseas students had certain occasionality.

The children sent to the United States were recalled back in halfway, so most of them failed to complete their studies in the United States. Only two students graduated from American universities with a degree. After they returned to China, they were discriminated against by traditional scholars and regarded as "foreign devil" and "people who are no good for the country", and their salary was very low. [22] This situation was not the original intention of those who initiated the Overseas Bureau.

Despite various incidents, after all, the Qing government sent young children to study in the United States in 1872, which set a precedent for overseas students in modern times. Before the Sino-Japanese War broke out in 1894, the Qing government chose to send four types of students to study abroad, include young children students, army students, ship administration students, and embassy students. Mr. Wang Jie said in the preface of the "Research on Rong Hong and the Children Studying in the United States": "Rong Hong and the children studying in the United States started hard, which inspired the upsurge of studying in Europe, Japan and France. The Chinese nation has emerged generations of elites to save and strengthen China when it was in crisis."

Generations of elites have sprung up and they changed the Chinese historical process from occasionality to necessity; behind these occasionalities, the call for corresponding regulations was getting higher and higher. An interesting thing is that in 1867, Bin Chun and Sun Jiagou were sent overseas for inspection and they saw that all Western countries have exchanged overseas students, so in the "China-US Renewal Treaty" (also known as "The Burlingame Treaty") signed in 1868, there was a provision that" The Chinese people who want to go to government schools of the United States to study all kinds of literature and art, shall have the same rights with people from the most favorable countries." [23] The Qing government who suffered all kinds of humiliations finally provided a treaty

prepared necessary conditions for Rong Hong's overseas education project. (Li Huaxing , "Rong Hong: The Outstanding Pioneer of Modern China", "Fudan Journal (Social Science Edition), 2005-5.)" 
[13] Feng Wei, “'The Antinomy' of the Qing Government's Policy of Encouraging Students to Study in Japan," Academic Research, 200410.

[14] Guo Hanmin, He Jinlin, "The Study Abroad Policy of late Qing Dynasty before the Sino-Japanese War of 1894-1895"

[15] Rong Shangqian, History of the Establishment of Overseas Bureau and of the Government-fund Students", p. 12.

[16] Rong Shangqian, History of the Establishment of Overseas Bureau and of the Government-fund Students", p.17.

[17] Rong Shangqian, History of the Establishment of Overseas Bureau and of the Government-fund Students", p. 7.

[18] The website of Ministry of Education of PRC http://www.moe.gov.cn/jyb_xxgk/moe_1777/moe_1779/201712/t201 71226 322582.html.

[19] Qinglian Website http://www.qlgov.org/40/66102.html.

[20] Shu Xincheng, "History of Overseas study in Modern China", Shanghai: Zhonghua Book Company, 1927, p. 2.

[21] Qu Tiehua, Chen Yanan, "A Study on the Motivation of the People for Choosing to Study Abroad in the Upsurge of Overseas Education in Modern China"

[22] Guo Hanmin, He Jinlin, "The Study Abroad Policy of late Qing Dynasty before the Sino-Japanese War of 1894-1895"

[23] Wang Tieya, "Compilation of Chinese and Foreign Old Charters", Beijing: SDX Joint Publishing Company, 1957, p.263.

[24] Guo Hanmin, He Jinlin, "The Study Abroad Policy of late Qing Dynasty before the Sino-Japanese War of 1894-1895"

\section{REFERENCES}

[1] Rong Shangqian, "History of the Establishment of Overseas Bureau and of the Government-fund Students" translated by Wang Minruo , Zhuhai Press, 2006

[2] Qu Tiehua, Chen Yanan, "A Study on the Motivation of the People for Choosing to Study Abroad in the Upsurge of Overseas Education in Modern China", "Journal of Hebei Normal University (Education Edition)", 2006-2.

[3] Guo Hanmin, He Jinlin, "The Study Abroad Policy in Late Qing Dynasty", "Journal of Changde Normal University (Social Science Edition)", 2000-3

[4] Zhou Guping, Zhu Shaoying, "Guo Bingwen and the Introduction of Modern American University Model", "Journal of Hebei Normal University (Education Science Edition)", 2005-5.

[5] Yan Gengwang, "Research Series of the History of Tang Dynasty", Hong Kong New Asia Research Institute, 1968, p. 431.

[6] Jiang Qingbo, "Study on the Nazhisuwei of Tang Dynasty", "Research on the History and Geography of China's Borderland", 2005-1.

[7] "History of the Three Kingdoms" Volume 44, "Jin Renwen".

[8] “Ce Fu Yuan Gui” Volume 996, "Foreign Department · Nazhi”.

[9] Guo Hanmin, He Jinlin, "The Study Abroad Policy of late Qing Dynasty before the Sino-Japanese War of 1894-1895"

[10] Hou Yaoxian, "The Position and Role of Westernization School in the History of Modern Chinese Education", "Journal of Baoji University of Arts and Sciences (Social Science Edition)", 2000-4.

[11] Zhu Gaozheng, "Chinese Culture and China's Future", East China Normal University Press, 2004, p.76-77.

[12] Rong Shangqian, "History of the Establishment of Overseas Bureau and of the Government-fund Students", p. 4. 